\title{
Neuropilin-I expression is associated with lymph node metastasis in breast cancer tissues
}

This article was published in the following Dove Press journal: Cancer Management and Research

\author{
Mahnaz Seifi-Alan' \\ Roshanak Shams' \\ Mojgan Bandehpour ${ }^{2}$ \\ Reza Mirfakhraie' \\ Soudeh Ghafouri-Fard' \\ 'Department of Medical Genetics, \\ Shahid Beheshti University of Medical \\ Sciences, Tehran, Iran; ${ }^{2}$ Department \\ of Biotechnology, School of Advanced \\ Technologies in Medicine, Shahid \\ Beheshti University of Medical \\ Sciences, Tehran, Iran
}

Purpose: Neuropilin-1 (NRP1) as an isoform-specific receptor for vascular endothelial growth factor and placenta growth factor in endothelial cells has been demonstrated to be expressed in breast cancer cells where it plays functional roles in cell survival, invasion, and migration. We hypothesized that an expression of NRP1 in breast cancer tissues is associated with clinicopathological data of patients and expression of the tumor suppressor miR-206.

Patients and methods: We evaluated the expression of NRP1 in 48 invasive ductal carcinomas of the breast and their corresponding adjacent noncancerous tissues (ANCTs) by means of real-time polymerase chain reaction. We also extracted data on miR-206 gene expression from the same cohort of patients to evaluate the correlation between expression levels of miR-206 and NRP1. In addition, we quantified NRP1 protein levels using the enzyme-linked immunosorbent assay technique.

Results: No significant difference was found in $N R P 1$ expression between tumoral tissues and ANCTs. We also assessed the associations between expression levels of NRP1 and clinicopathological data of patients and found no significant associations between NRP1 transcript levels and any characteristic. However, NRP1 protein concentrations were significantly higher in patients with lymph node involvement compared with those without lymph node involvement. No correlation was found between NRP1 and miR-206 expression levels.

Conclusion: NRP1 protein levels might be an indicator of metastasis potential in breast cancer. Future studies are needed to confirm these results in larger cohorts of patients.

Keywords: NRP1, neuropilin-1, breast cancer

\section{Introduction}

Breast cancer, as the most prevalent cancer among women, ${ }^{1}$ has been associated with a significant mortality rate. ${ }^{2}$ Despite much research, ${ }^{3-5}$ only few biomarkers or therapeutic targets have been approved, altering the ordinary practice of oncology. ${ }^{6}$ Therefore, continuous efforts are being made in the field of identification of biomarkers for this type of human malignancy. Neuropilin-1 (NRP1) as an isoform-specific receptor for vascular endothelial growth factor (VEGF) and placenta growth factor (PlGF) in endothelial cells has been demonstrated to be expressed in breast cancer cells where it plays functional roles in cell survival, invasion, and migration. ${ }^{7}$ In the context of cancer, NRP1 also regulates angiogenesis and the epithelial-to-mesenchymal transition (EMT) mechanisms through interactions with VEGF, and its receptors, PlGF and transforming growth factor $\beta 1$ (TGF- $\beta 1) .{ }^{8}$ Moreover, NRP1 has been shown to be a target of regulation by the tumor suppressor miR-206 in estrogen receptor-positive
Correspondence: Soudeh Ghafouri-Fard Department of Medical Genetics, Shahid Beheshti University of Medical Sciences, Daneshjoo Boulevard, Velenjak, Tehran 19857-17443, Iran

Tel/Fax +98 2I 23872572

Email s.ghafourifard@sbmu.ac.ir 
cell lines, MCF-7 and T47D. The inhibitory effects of miR206 overexpression on the migration and invasive potentials of these cells are at least partly due to its suppressive effect on NRP1 expression. ${ }^{9}$ Taken together, these data suggest an oncogenic role for NRP1 in the pathogenesis of breast cancer and pinpoint it as a target of a functional tumor-suppressive microRNA (miRNA). Therefore, we designed a study to assess NRP1 expression at both RNA and protein levels in correlation with expression level of miR-206. We also extracted microarray gene expression data to compare those results with our expression data results.

\section{Materials and methods}

\section{Patients' samples}

The expression study was performed on 48 tumoral tissues and their corresponding adjacent noncancerous tissues (ANCTs) obtained during surgery from patients with a definite diagnosis of invasive ductal carcinoma of the breast. Normal-appearing adjacent breast tissues were excised at least $2 \mathrm{~cm}$ away from the invasive tumor margin and were assessed by the pathologist to not contain tumoral cells. Tissues were obtained from Sina Hospital and Farmanieh Hospital (Tehran, Iran) during 2017. All patients signed an informed consent form. It was confirmed that the patients did not receive any kind of anticancer treatment before the surgery. The study protocol was approved by the ethical committee of Shahid Beheshti University of Medical Sciences (IR.SBMU.MSP.REC.1396.153).

\section{RNA extraction and real-time polymerase chain reaction (PCR)}

Total RNA was extracted from all samples using the

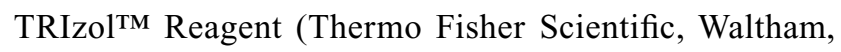
MA, USA) according to the protocol provided by the company. cDNA was synthesized from extracted RNA samples using RevertAid First Strand cDNA Synthesis Kit (Thermo Fisher Scientific). Relative transcript levels of NRPl were quantified using SYBR ${ }^{\circledR}$ Premix Ex Taq ${ }^{\mathrm{TM}}$ (TaKaRa, Otsu, Japan) on the Rotor Gene 6000 Corbett Real-Time PCR system. B2M gene was used as the normalizer. All experiments were carried out in duplicate. The nucleotide sequences of primers used for amplification of NRP1 and $B 2 M$ are as follows: NRP1 forward primer: 5'-CTCCAACGGGGAAGACTGGA-3', reverse primer: 5'-GTTGCAGGCTTGATTCGGAC-3'; B2M forward primer: 5'-AGATGAGTATGCCTGCCGTG-3', reverse primer: 5'-GCGGCATCTTCAAACCTCCA-3'.

\section{NRPI tissue concentration}

NRP1 tissue concentration was evaluated using the human NRP1 enzyme-linked immunosorbent assay (ELISA) kit (MyBiosource, San Diego, CA, USA) which uses the biotin double-antibody sandwich technology. The values of NRP1 are shown in $\mathrm{pg} / \mathrm{mL}$ and defined as mean \pm standard error of mean.

\section{Extraction of microarray data}

We retrieved GSE5926 and GSE5927 microarray gene expression data through application of the Gene Expression Omnibus repository at the National Center for Biotechnology Information archives. ${ }^{10}$ Expression of NRP1 gene was compared between breast cancer patients and normal samples using the GEO2R web tool (https:/www.ncbi.nlm.nih.gov/geo/info/ geo2r.html). Finally, we evaluated the correlations between expression of NRP1 and expression of miR-206 as a validated regulator of $N R P 1$ in the mentioned microarray datasets.

\section{Statistical analysis}

R software (version 3.3.1; Vienna, Austria) was used for statistical analysis. Data were presented as mean \pm standard deviation. Differences in NRP1 mRNA expression were evaluated using Student's paired $t$-tests and Wilcoxon signed-rank test based on the presence or absence of normal distribution in data, respectively. The association of clinicopathological and demographic data with expression levels of NRP1 was evaluated using a chi-squared test, Student's $t$-test and oneway analysis of variance. The value of $2^{-\Delta \Delta \mathrm{Ct}}$ was estimated to calculate the expression fold change for each gene. The cutoffs of the fold change values were calculated based on the median values of fold changes. Spearman's rank correlation coefficient was used for evaluation of the correlations between NRP1 protein concentration and relative expression of its mRNA and miR-206. For all statistical tests, the level of significance was set at $P<0.05$.

\section{Results \\ General demographic and clinical data of patients}

The current study included 48 patients with invasive ductal carcinomas of the breast whose detailed demographic and clinical data are shown in Table 1.

\section{Relative expression of NRPI in tumoral tissues compared with ANCTs}

No significant difference was found in NRP1 expression between tumoral tissues and ANCTs (Figure 1). 
Table I General demographic and clinical data of patients

\begin{tabular}{|c|c|c|}
\hline Variables & Groups & $\begin{array}{l}\text { Number of } \\
\text { cases (\%) }\end{array}$ \\
\hline \multirow[t]{2}{*}{ Age (years) } & $<50$ & $21(44)$ \\
\hline & $\geq 50$ & $27(56)$ \\
\hline \multirow[t]{3}{*}{ Body mass index $\left(\mathrm{kg} / \mathrm{m}^{2}\right)$} & $<25$ & $2(4)$ \\
\hline & $25-29$ & $24(50)$ \\
\hline & $>29$ & $22(46)$ \\
\hline \multirow[t]{2}{*}{ Menopause status } & Post & $37(77)$ \\
\hline & Pre & II (23) \\
\hline \multirow[t]{4}{*}{ Stage } & 1 & II (23) \\
\hline & II & $18(37.5)$ \\
\hline & III & $16(33)$ \\
\hline & IV & $3(6.5)$ \\
\hline \multirow[t]{3}{*}{ Histological grade } & 1 & $7(14.5)$ \\
\hline & II & $25(52)$ \\
\hline & III & $16(33.5)$ \\
\hline \multirow[t]{3}{*}{ Mitotic rate } & 1 & $19(39.5)$ \\
\hline & 2 & $22(46)$ \\
\hline & 3 & $7(14.5)$ \\
\hline \multirow[t]{3}{*}{ Tumor size $(\mathrm{cm})$} & $<2$ & $18(37.5)$ \\
\hline & $2-5$ & $22(46)$ \\
\hline & $>5$ & $8(16.5)$ \\
\hline \multirow[t]{2}{*}{ Lymph node involvement } & Positive & $19(39.5)$ \\
\hline & Negative & $29(60.5)$ \\
\hline \multirow[t]{2}{*}{ HER2 status } & Positive & $36(75)$ \\
\hline & Negative & $12(25)$ \\
\hline \multirow[t]{2}{*}{ ER status } & Positive & $37(77)$ \\
\hline & Negative & II (23) \\
\hline \multirow[t]{2}{*}{ PR status } & Positive & $35(73)$ \\
\hline & Negative & $13(27)$ \\
\hline
\end{tabular}

Abbreviations: HER2, human epidermal growth factor receptor 2; ER, estrogen receptor; PR, progesterone receptor.
We also assessed the associations between expression levels of NRPI and clinicopathological data of patients and found no significant associations between NRP1 transcript levels and any characteristic (Table 2).

\section{Assessment of NRPI protein concentrations}

NRP1 protein levels were quantified using a commercial ELISA kit in different subgroups of tumoral samples. Table 3 demonstrates the mean values of its expression in relation to patients' clinicopathological data. NRP1 protein concentrations were significantly higher in patients with lymph node involvement compared with those without lymph node involvement $(P=0.03)$. However, NRP1 protein concentrations were not associated with other clinicopathological or demographic data.

\section{Assessment of NRPI expression in GSE5926 dataset}

We also evaluated NRPI expression levels in GSE5926 dataset and found significant downregulation of NRP1 in in situ tumors compared with normal sample $(P=0.02)$. However, no significant difference was found in its expression between invasive and in situ tumors $(P=0.35)$ or between invasive and normal tissues $(P=0.11)$ (Table 4$)$.

We also compared NRP1 expression in different molecular subtypes of breast tumors and normal sample and found

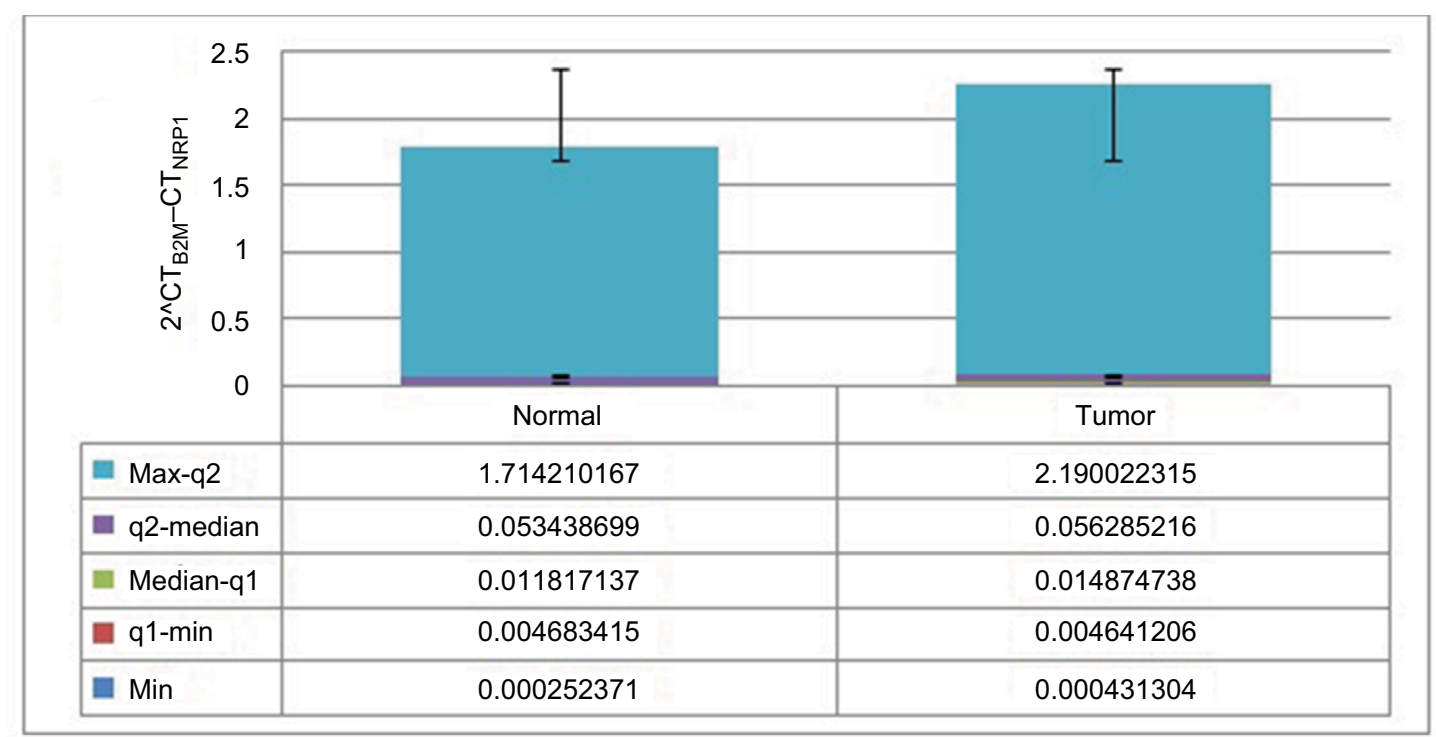

Figure I Relative expression of NRPI in tumoral and ANCTs.

Abbreviation: NRPI, neuropilin-I; ANCTs, adjacent noncancerous tissues. 
Table 2 Association of NRPI transcript levels with patients' clinicopathological data

\begin{tabular}{|c|c|c|c|}
\hline Variable & $\begin{array}{l}\text { Number of } \\
\text { cases }\end{array}$ & $\begin{array}{l}\text { NRPI high } \\
\text { level }\end{array}$ & $P$-value \\
\hline \multicolumn{4}{|l|}{ Age (years) } \\
\hline$<50$ & 21 (44\%) & 11 & \multirow[t]{2}{*}{ NS } \\
\hline$\geq 50$ & 27 (56\%) & 17 & \\
\hline \multicolumn{4}{|c|}{ Body mass index $\left(\mathrm{kg} / \mathrm{m}^{2}\right)$} \\
\hline $25-29$ & 24 (50\%) & 14 & \multirow[t]{2}{*}{ NS } \\
\hline$>29$ & $22(46 \%)$ & 13 & \\
\hline \multicolumn{4}{|l|}{ Menopause status } \\
\hline Post & 37 (77\%) & 21 & \multirow[t]{2}{*}{ NS } \\
\hline Pre & II (23\%) & 7 & \\
\hline \multicolumn{4}{|l|}{ Stage } \\
\hline I & II (23\%) & 4 & \multirow[t]{4}{*}{ NS } \\
\hline II & I8 (37.5\%) & 14 & \\
\hline III & $16(33 \%)$ & 6 & \\
\hline IV & 3 (6.5\%) & 2 & \\
\hline \multicolumn{4}{|l|}{ Histological grade } \\
\hline $\mathrm{I}$ & 7 (I4.5\%) & 4 & \multirow[t]{3}{*}{ NS } \\
\hline II & $25(52 \%)$ & 15 & \\
\hline III & $16(33.5 \%)$ & 7 & \\
\hline \multicolumn{4}{|l|}{ Mitotic rate } \\
\hline 1 & 19 (39.5\%) & 10 & \multirow[t]{3}{*}{ NS } \\
\hline 2 & $22(46 \%)$ & 10 & \\
\hline 3 & 7 (I4.5\%) & 6 & \\
\hline \multicolumn{4}{|l|}{ Tumor size $(\mathrm{cm})$} \\
\hline$\leq 2$ & I8 (37.5\%) & 9 & \multirow[t]{3}{*}{ NS } \\
\hline $2-5$ & $22(46 \%)$ & 12 & \\
\hline$\geq 5$ & $8(16.5 \%)$ & 5 & \\
\hline \multicolumn{4}{|c|}{ Lymph node involvement } \\
\hline Positive & $19(39.5 \%)$ & 10 & \multirow[t]{2}{*}{ NS } \\
\hline Negative & $29(60.5 \%)$ & 16 & \\
\hline \multicolumn{4}{|l|}{ HER2 } \\
\hline Positive & $25(75 \%)$ & 16 & \multirow[t]{2}{*}{ NS } \\
\hline Negative & $23(25 \%)$ & 10 & \\
\hline \multicolumn{4}{|l|}{ ER } \\
\hline Positive & 37 (77\%) & 21 & \multirow[t]{2}{*}{ NS } \\
\hline Negative & II (23\%) & 5 & \\
\hline \multicolumn{4}{|l|}{$\mathrm{PR}$} \\
\hline Positive & $35(73 \%)$ & 19 & \multirow[t]{2}{*}{ NS } \\
\hline Negative & $13(27 \%)$ & 7 & \\
\hline \multicolumn{4}{|c|}{ Breast cancer phenotype } \\
\hline Luminal A & 19 (39.5\%) & 11 & \multirow[t]{4}{*}{0.891} \\
\hline Luminal B & $22(46 \%)$ & 13 & \\
\hline HER2 & $2(4 \%)$ & 1 & \\
\hline Triple negative & $5(10.5 \%)$ & 3 & \\
\hline
\end{tabular}

Note: NRPI high level was defined based on the cut-offs of the fold changes in tumoral tissue vs. the corresponding ANCT, and the median value of fold changes was set as cutoff.

Abbreviations: NRPI, neuropilin-I; ANCT, adjacent noncancerous tissue; HER2, human epidermal growth factor receptor 2; ER, estrogen receptor; PR, progesterone receptor; NS, not significant.

significant downregulation of NRP1 in human epidermal growth factor receptor 2-positive, basal-like, luminal A and luminal B subtypes compared with normal sample. However, NRP1 expression was not significantly different between normal-like breast tumor and normal samples (Table 5).
Table 3 The association between NRPI protein concentration and demographic and clinicopathological characteristics of patients

\begin{tabular}{|c|c|c|}
\hline $\begin{array}{l}\text { Patient/tumor } \\
\text { characteristics }\end{array}$ & $\begin{array}{l}\text { NRP I concentration } \\
\text { (mean values } \pm \text { standard } \\
\text { error of mean, } \mathrm{pg} / \mathrm{mL} \text { ) }\end{array}$ & $P$-value \\
\hline \multicolumn{3}{|l|}{ Age (years) } \\
\hline$<50$ & $27.99 \pm 10.39$ & 0.59 \\
\hline$\geq 50$ & $38.24 \pm 16.35$ & \\
\hline \multicolumn{3}{|c|}{ Body mass index $\left(\mathrm{kg} / \mathrm{m}^{2}\right)$} \\
\hline $25-29$ & $33.44 \pm 13.97$ & 0.92 \\
\hline$>29$ & $35.54 \pm 14.67$ & \\
\hline \multicolumn{3}{|l|}{ Menopause status } \\
\hline Post & $39.9 \pm 14.85$ & 0.39 \\
\hline Pre & $21.84 \pm 8.85$ & \\
\hline \multicolumn{3}{|l|}{ TNM stage } \\
\hline 1 & $|5.7| \pm 7.77$ & 0.39 \\
\hline II & $20.50 \pm 11.52$ & \\
\hline III & $57.96 \pm 20.81$ & \\
\hline IV & 0 & \\
\hline \multicolumn{3}{|l|}{ Histological grade } \\
\hline 1 & 0 & 0.78 \\
\hline II & $31.62 \pm 13.13$ & \\
\hline III & $40.42 \pm 16.35$ & \\
\hline \multicolumn{3}{|l|}{ Mitotic rate } \\
\hline I & $28.90 \pm 14.54$ & 0.49 \\
\hline 2 & $27.89 \pm 14.43$ & \\
\hline 3 & $61.95 \pm 26.66$ & \\
\hline \multicolumn{3}{|l|}{ Tumor size $(\mathrm{cm})$} \\
\hline$\leq 2$ & $21.61 \pm 14.8$ & 0.607 \\
\hline $2-5$ & $46.02 \pm 17.02$ & \\
\hline$\geq 5$ & $26.95 \pm 26.95$ & \\
\hline \multicolumn{3}{|c|}{ Lymph node involvement } \\
\hline Positive & $66.44 \pm 24.33$ & 0.03 \\
\hline Negative & $18.33 \pm 7.32$ & \\
\hline \multicolumn{3}{|l|}{ HER2 } \\
\hline Positive & $35.71 \pm 14.16$ & 0.52 \\
\hline Negative & $22.58 \pm 9.95$ & \\
\hline \multicolumn{3}{|l|}{ ER } \\
\hline Positive & $36.67 \pm 12.46$ & 0.57 \\
\hline Negative & $20.21 \pm 14.32$ & \\
\hline \multicolumn{3}{|l|}{ PR } \\
\hline Positive & $27.43 \pm 8.44$ & 0.37 \\
\hline Negative & $46.91 \pm 27.21$ & \\
\hline \multicolumn{3}{|c|}{ Breast cancer phenotype } \\
\hline Luminal A & || $.42 \pm 4.8 \mid$ & 0.205 \\
\hline Luminal B & $52.26 \pm 19.57$ & \\
\hline HER2 & 0 & \\
\hline Triple negative & 0 & \\
\hline
\end{tabular}

Abbreviations: NRPI, neuropilin-I; HER2, human epidermal growth factor receptor 2; ER, estrogen receptor; PR, progesterone receptor.

\section{Assessment of correlation between NRPI and miR-206 expressions}

We also retrieved data of miR-206 expression from the same cohort of patients (Seifi et al, unpublished data, 2017) and assessed the correlations between NRP1 expression levels 
and those of miR-206. No significant correlation was found between miR-206 and NRP1 transcript levels (Spearman's correlation coefficient $=-0.0004, P=0.92$ ) or between miR206 and NRP1 protein levels (Spearman's correlation coefficient $=-0.140, P=0.469)$. Also, the same analysis in the microarray datasets showed no correlation between transcript levels of miR-206 and NRP1 (Spearman's correlation coefficient $=-0.004, P=0.98$ ). In addition, no correlation was found between mRNA and protein levels of NRP1 (Spearman's correlation coefficient $=-0.111, P=0.544$ ).

\section{Discussion}

In this study, we compared the expression of $N R P 1$ transcript between breast tumor tissues and ANCTs and found no significant difference in its expression levels between these sets of samples. We also retrieved gene expression data from GSE5926 dataset and found significant downregulation of $N R P 1$ in in situ tumors compared with normal sample but no significant difference in its expression between invasive and in situ tumors or between invasive and normal tissues. Our results are in contrast with Ferrario et al's study, which, through immunohistochemical staining of a breast tissue microarray, has shown significantly higher expression of NRP1 in malignant epithelium compared with benign and preinvasive breast lesions. ${ }^{7}$ Such inconsistency between our experimental results and the results of the mentioned study might be due to the difference in selection of control tissues (ANCTs vs. normal tissues). Aran et al recently assessed the transcriptomes of healthy tissues, ANCTs, and tumor tissues. ${ }^{11}$ They found that ANCTs show a distinctive intermediate expression profile between healthy and tumor tissues. More importantly, they observed activation of genes related to hypoxia, tumor necrosis factor $\alpha$ and TGF- $\beta$ signaling, apoptosis, EMT, and angiogenesis in adjacent epithelium. Consequently, a relatively similar expres-

Table 4 Relative expression of NRPI in invasive, in situ, and normal samples included in the GSE5926 dataset

\begin{tabular}{llll}
\hline & $\begin{array}{l}\text { Invasive vs. } \\
\text { in situ }\end{array}$ & $\begin{array}{l}\text { Invasive vs. } \\
\text { normal }\end{array}$ & $\begin{array}{l}\text { In situ vs. } \\
\text { normal }\end{array}$ \\
\hline Fold change & 0.23 & -1.08 & -1.15 \\
$P$-value & 0.35 & 0.11 & 0.02 \\
\hline
\end{tabular}

Abbreviation: NRPI, neuropilin-I. sion of NRP1 in tumoral tissues and ANCTs, as revealed in our study, as well as the similar expression of NRPI in invasive and in situ tumors, as obtained from analysis of microarray dataset, might be explained by activation of the mentioned pathways in ANCTs. However, due to the low number of normal tissues in the GSE5926 dataset, ${ }^{12}$ the analysis between normal tissues and other types of tissues might be biased.

Noticeably, we found significantly higher expression of NRP1 in lymph node-positive patients compared with lymph node-negative patients. We also detected a trend toward higher NRP1 levels in higher stages and histological grades, but perhaps due to the small sample size, it did not reach the level of significance. Such observation is in line with previous assays which showed the role of another receptor for VEGF, NRP2, in cell migration and metastasis. ${ }^{13}$ Moreover, in vivo and in vitro studies have indicated the effectiveness of NRP1 inhibition in suppression of breast-cancer-related metastasis. ${ }^{14}$ More recently, higher plasma NRP1 levels were detected in breast cancer patients with advanced diseased nodes compared with patients with no nodal metastasis, those with less advanced nodal metastasis, and healthy subjects. ${ }^{8}$

Finally, we assessed the correlation between the mRNA and protein levels of NRP1 as well as those of NRP1 and miR-206 and found no correlation between any of them. The lack of correlation between mRNA and protein levels of a certain gene has been reported previously. ${ }^{15} \mathrm{~A}$ more recent study showed that mRNA and protein levels do not correlate well except when a gene-specific RNA-to-protein conversion factor is applied to improve the predictability of protein copy numbers from transcript levels. ${ }^{16}$ The dimensional and chronological alterations of mRNAs, along with the regional accessibility of resources for protein production, would affect the correlation between transcript and protein levels of a certain gene in many situations such as cancer. ${ }^{17}$

Despite the fact that NRP1 has been validated as a target of miR-206 in cell line studies, ${ }^{9}$ both in silico analysis of microarray data and assessment of our gene expression results showed no correlation between NRP1 and miR-206 levels. This observation can be explained by the inhibitory effect of several miRNAs on NRP1 expression. To provide evidence for such hypothesis, we used the miRWalk 2.0 tool $^{18}$ to obtain the list of miRNAs that target NRP1 based on evaluation of

Table 5 Relative expression of NRPI in HER2+, basal-like, luminal A, luminal B, and normal-like subtypes compared with normal sample included in the GSE5926 dataset

\begin{tabular}{llllll}
\hline & HER2+ vs. normal & Basal vs. normal & Luminal A vs. normal & Luminal B vs. normal & Normal-like vs. normal \\
\hline Fold change & -1.09 & -1.53 & -1.55 & -1.15 & -0.92 \\
$P$-value & 0.011 & 0.001 & 0.005 & 0.0002 & 0.14 \\
\hline
\end{tabular}

Abbreviations: NRPI, neuropilin-I; HER2, human epidermal growth factor receptor 2. 
miRNA-binding sites within the complete sequence of NRP1, as well as search for experimentally verified miRNA-NRP1 interaction data. We found that numerous miRNAs including miR-181, miR-335, miR-124, miR-16, miR-186, miR218, miR-338, and miR-320 target NRP1. Therefore, the expression level of NRP1 is influenced by numerous factors. Besides, in silico analysis of National Cancer Institute-60 expression data has revealed more negative correlations between miRNA and mRNA expression profiles in cases where the miRNA degrades the corresponding mRNA compared with situations when the miRNA inhibits the translation of its target gene. ${ }^{19}$ Therefore, the lack of correlation between miR-206 and NRP1 levels can be explained by the possible effect of miR-206 on translation of NRP1. Future studies are needed to elaborate the underlying mechanism.

\section{Conclusion}

This study provides evidence for superiority of protein levels over mRNA levels of NRP1 as a predictive marker in breast cancer. NRP1 protein levels might be an indicator of metastasis potential in breast cancer. Future studies are needed to confirm these results in larger cohorts of patients.

\section{Acknowledgments}

This work was financially supported by the Research Department of the School of Medicine Shahid Beheshti University of Medical Sciences (grant no. 9641). This article has been extracted from the thesis written by Mahnaz Seifi-Alan in School of Medicine, Shahid Beheshti University of Medical Sciences (Registration No. 105M).

\section{Disclosure}

The authors report no conflicts of interest in this work.

\section{References}

1. Seifi-Alan M, Shamsi R, Ghafouri-Fard S, et al. Expression analysis of two cancer-testis genes, FBXO39 and TDRD4, in breast cancer tissues and cell lines. Asian Pac J Cancer Prev. 2014;14(11):6625-6629.
2. Ghafouri-Fard S, Shamsi R, Seifi-Alan M, Javaheri M, Tabarestani S. Cancer-testis genes as candidates for immunotherapy in breast cancer. Immunotherapy. 2014;6(2):165-179.

3. Dianatpour A, Faramarzi S, Geranpayeh L, Mirfakhraie R, Motevaseli E, Ghafouri-Fard S. Expression analysis of AFAP1-AS1 and AFAP1 in breast cancer. Cancer Biomark. 2018;22(1):49-54.

4. Sarrafzadeh S, Geranpayeh L, Ghafouri-Fard S. Expression analysis of long non-coding PCAT-1 in breast cancer. Int J Hematol Oncol Stem Cell Res. 2017;11(3):185-191.

5. Nikpayam E, Soudyab M, Tasharrofi B, et al. Expression analysis of long non-coding ATB and its putative target in breast cancer. Breast Dis. 2017;37(1):11-20.

6. Perez-Gracia JL, Sanmamed MF, Bosch A, et al. Strategies to design clinical studies to identify predictive biomarkers in cancer research. Cancer Treat Rev. 2017;53:79-97.

7. Ferrario C, Hostetter G, Bouchard A, Huneau M-C, Mamo A, Basik M. Expression of neuropilin-1 and related proteins in breast cancer. Proc Amer Assoc Cancer Res. 2006;47:5034.

8. Naik A, Al-Zeheimi N, Bakheit CS, et al. Neuropilin-1 associated molecules in the blood distinguish poor prognosis breast cancer: a cross-sectional study. Sci Rep. 2017;7(1):3301.

9. Yin K, Yin W, Wang Y, et al. MiR-206 suppresses epithelial mesenchymal transition by targeting TGF-beta signaling in estrogen receptor positive breast cancer cells. Oncotarget. 2016;7(17):24537-24548.

10. Barrett T, Edgar R. Gene expression omnibus: microarray data storage, submission, retrieval, and analysis. Method Enzymol. 2006;411: 352-369.

11. Aran D, Camarda R, Odegaard J, et al. Comprehensive analysis of normal adjacent to tumor transcriptomes. Nat Commun. 2017;8: 1077.

12. Lesurf R, Aure MR, Mork HH, et al. Molecular features of subtypespecific progression from ductal carcinoma in situ to invasive breast cancer. Cell Rep. 2016;16(4):1166-1179.

13. Yasuoka H, Kodama R, Tsujimoto M, et al. Neuropilin-2 expression in breast cancer: correlation with lymph node metastasis, poor prognosis, and regulation of CXCR4 expression. BMC Cancer. 2009;9:220.

14. Arpel A, Gamper C, Spenle C, et al. Inhibition of primary breast tumor growth and metastasis using a neuropilin-1 transmembrane domain interfering peptide. Oncotarget. 2016;7(34):54723-54732.

15. Kendrick N. A Gene's mRNA Level Does not Usually Predict Its Protein Level. Madison, WI: Kendricklabs.com; 2014.

16. Edfors F, Danielsson F, Hallstrom BM, et al. Gene-specific correlation of RNA and protein levels in human cells and tissues. Mol Syst Biol. 2016;12(10):883.

17. Liu Y, Beyer A, Aebersold R. On the dependency of cellular protein levels on mRNA abundance. Cell. 2016;165(3):535-550.

18. Dweep H, Gretz N. miRWalk2.0: a comprehensive atlas of microRNAtarget interactions. Nat Methods. 2015;12(8):697.

19. Wang YP, Li KB. Correlation of expression profiles between microRNAs and mRNA targets using NCI-60 data. BMC Genomics. 2009; $10: 218$.
Cancer Management and Research

Publish your work in this journal

Cancer Management and Research is an international, peer-reviewed open access journal focusing on cancer research and the optimal use of preventative and integrated treatment interventions to achieve improved outcomes, enhanced survival and quality of life for the cancer patient. The manuscript management system is completely online and includes

\section{Dovepress}

a very quick and fair peer-review system, which is all easy to use. Visit http://www.dovepress.com/testimonials.php to read real quotes from published authors. 